\title{
Regional Climate Model Simulations of the 1998 Summer China Flood: Dependence on Initial and Lateral Boundary Conditions
}

\author{
Shuyan Liu ${ }^{*}, 1$, Xin-Zhong Liang ${ }^{1,2}$, Wei Gao ${ }^{3,4}$, Yuxiang He ${ }^{1}$, Tiejun Ling ${ }^{5}$ \\ ${ }^{I}$ Earth System Science Interdisciplinary Center, University of Maryland, USA \\ ${ }^{2}$ Department of Atmospheric and Oceanic Sciences, University of Maryland, USA \\ ${ }^{3}$ USDA-UVB Monitoring and Research Program, Natural Resource Ecology Laboratory, Colorado State University, \\ Fort Collins, USA \\ ${ }^{4}$ Joint Laboratory for Environmental Remote Sensing and Data Assimilation, East China Normal University and Center \\ for Earth Observation and Digital Earth, Chinese Academy of Sciences, Shanghai, China \\ ${ }^{5}$ National Marine Environmental Forecasting Center, Beijing, China
}

\begin{abstract}
The dependence of the RegCM3 (Regional Climate Model version 3) downscaling skill on initial conditions (ICs) and lateral boundary conditions (LBCs) are investigated for the 1998 summer flood along the Yangtze River Basin in China. The effect of IC uncertainties is depicted by 15 realizations starting on each consecutive day from April 1 to 15 while all ending on September 1, 1998 with identical driving LBCs, analyses are based on June, July and August simulations. The result reveals certain IC effect on precipitation for daily evolution but little for summer mean geographical distribution. In contrast, the effect of LBCs uncertainties as represented by four different reanalyses are notably larger in both daily evolution and summer mean distribution. The ensemble average among either 15 IC realizations or 4 LBC runs does not show important skill improvement over the individuals. None of the RegCM3 simulations (including the ensemble means) captured the observed main rain band along the Yangtze River Basin. This general failure suggests the need for further model physics improvement.
\end{abstract}

Keywords: Ensemble, Initial condition, Lateral boundary condition, RegCM, regional climate model, Yangtze River Basin.

\section{INTRODUCTION}

Since Lorenz [1] first found that the atmosphere is a highly nonlinear system causing numerical solutions to be sensitive to small perturbations in initial conditions (ICs), and as computational capability is rapidly increasing, ensemble weather forecasts are becoming a common operational practice (Toth and Kalnay [2]; Mullen et al. [3]). A similar procedure has now also been taken in the general circulation model (GCM) community to construct ensemble climate predictions.

A Regional Climate Model (RCM) not only requires ICs at the initial step, but also time-dependent lateral boundary conditions (LBCs) which provide large-scale atmospheric circulation through buffer zones that drive the development of mesoscale systems inside the RCM domain. Both ICs and LBCs can be provided by GCM simulations. Since LBCs are required throughout the integration period, LBC-related errors can have long-term and damaging effects on RCM results (Warner et al. [6]). Effective LBC data assimilation techniques that accurately integrate LBCs across the buffer zones and a physically-based domain design critically determine the RCM performance (Liang et al. [4]). On the

*Address correspondence to this author at the Earth System Science Interdisciplinary Center, University of Maryland, 5825 University Research Court Suite 4001, College Park, MD 20740, USA; Tel: 301 405-1522; Fax: 301 405-8468; E-mail: liusy@umd.edu other hand, certain RCM skill sensitivities to ICs, causing internal variability that may modulate or even mask physically forced signals (Giorgi and Bi [5]). LBC plays a critical role in RCM simulations, while IC impacts generally decreases with the simulation length (Wu et al. [7]). This study compares the relative contributions from uncertainties in ICs and LBCs to the RCM climate simulations for the 1998 summer China flood.

The study of ICs' effects on RCM through internal variability conducted by Giorgi and $\mathrm{Bi}$ [5] constructed different ICs and LBCs by adding random perturbations on the European Center for Medium-Range Weather Forecast (ECMWF) observational reanalysis (ERA; Gibson et al. [8]). In contrast, the present study uses 15 consecutive days during April 1-15 to initialize the RCM from the National Centers for Environmental Prediction Department of Energy (NCEP/DOE) Atmospheric Model Intercomparison Project (AMIP) II reanalysis (R-2; Kanamitsu et al. [9]) to depict the IC uncertainties. LBCs uncertainties are specified by differences among R-2, ERA, ERA Interim reanalysis (ERI, Dee et al. [10]) and Japanese 25-year reanalysis (JRA, Onogi et al. [11]). The RCM sensitivities to these ICs and LBCs uncertainties are investigated for the summer of 1998 when severe flooding occurred along the Yangtze River Basin. This case has been identified with active convection at regional to local scales under strong anomalous planetary forcings (Samel and Liang [12]) and thus is ideal for 
evaluation of RCM performance (Wang et al. [13]; Liu et al. $[14,15])$.

Section 2 describes the model configuration and experiment design. Section 3 and 4 depict the RCM result dependence on ICs and LBCs focusing on precipitation and surface air temperature. Section 5 gives the conclusion.

\section{MODEL CONFIGURATION AND EXPERIMENT DESIGN}

The RCM for this study is the RegCM3 (Elguindi et al. [16], available from http://users.ictp.it/ pubregcm/RegCM3/), which is widely used for regional climate downscaling over China (Wang et al. [13]; Liu et al. [14, 15]). It was developed from the fifth-generation Pennsylvania State University-National Center for Atmospheric Prediction (PSU-NCAR) Mesoscale Model (MM5) hydrostatic dynamic core coupled with physics parameterization schemes suitable for climate applications (Dudhia et al. [17]).

The physics configuration chosen in this study is as follows. Cumulus convection is parameterized by the Grell [18] scheme. Non-convective precipitation and clouds are resolved by the explicit microphysics scheme of Pal et al. [19]. The longwave and shortwave radiative transfer is represented by the National Center for Atmospheric Research (NCAR) Community Climate Model (CCM3) scheme (Kiehl et al. [20]). The planetary boundary layer is treated by the nonlocal diffusion scheme of Holtslag and Boville [21]. The land surface processes are modeled by the Biosphere-Atmosphere Transfer Scheme version 1e (BATS; Dickinson et al. [22]). The U.S. Geological Survey (USGS) 10-min topographic data, and the BATS 20 vegetation classifications are used to define, respectively, the representative terrain height and the dominant land cover for each grid box.

The RCM has 18 vertical layers with the model top at $100 \mathrm{hPa}(\sim 16.3 \mathrm{~km}$ above the sea level). Its computational domain is centered at $\left(35.18^{\circ} \mathrm{N}, 110^{\circ} \mathrm{E}\right)$ and covers China by a $30-\mathrm{km}$ horizontal grid distance using the Lambert conformal map projection. Fig. (1) illustrates the domain design. The buffer zones are located across 12 grids along each of the 4 domain edges, where LBCs are specified throughout the integration period using a dynamic relaxation technique (Giorgi et al. [23]). This domain has been shown to produce the most skillful simulation of the 1998 summer precipitation distribution over China (Liu et al. [14, 15]). Outlined in Fig. (1) are also four key regions (South, Yangtze River Basin, North, and Northeast) that have been identified as having distinct climate regimes and precipitation characteristics relating to the China summer monsoon precipitation (Mei-yu) (Ding [24]). Generally, the Mei-yu rainband arrives in the South during late May and early June, advances to the Yangtze River Basin in middle and late June, and then to the North in July, and to the Northeast in August (Samel et al. [25]). This study will elaborate model result sensitivities over these representative regions.

To depict the effect of IC uncertainties, 15 RCM runs were conducted for continuous integrations starting consecutively from April 1 to 15 while all ending on September 1, 1998. These ICs are provided by the same R-2 that constructs the LBCs during the entire integration period. Thus, a set of 15 realizations that differ only by their initial

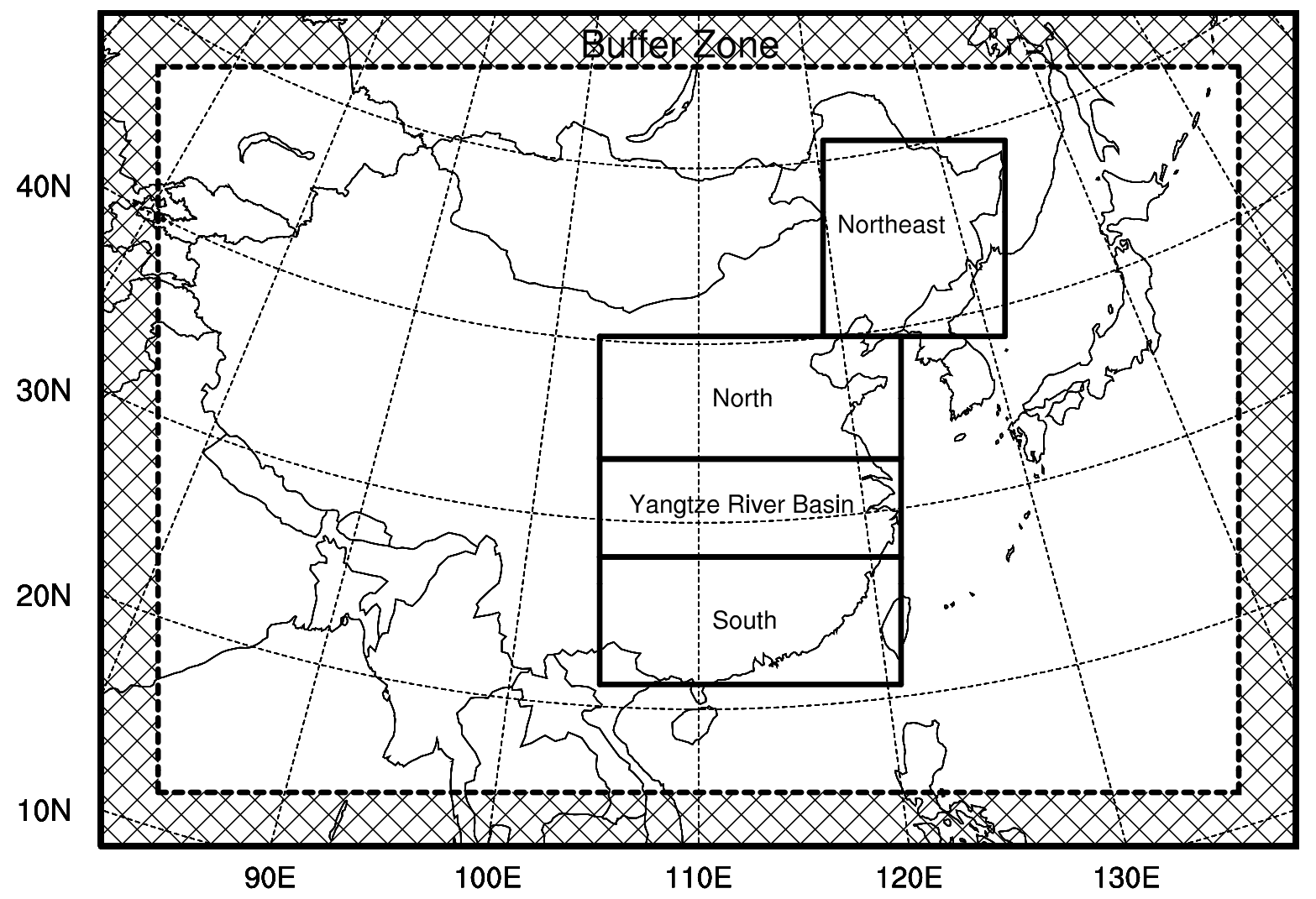

Fig. (1). Computational domain and 4 sub-regions (Northeast, North, Yangtze River Basin and South). Hatched lines denote the buffer zones where LBCs are specified. 

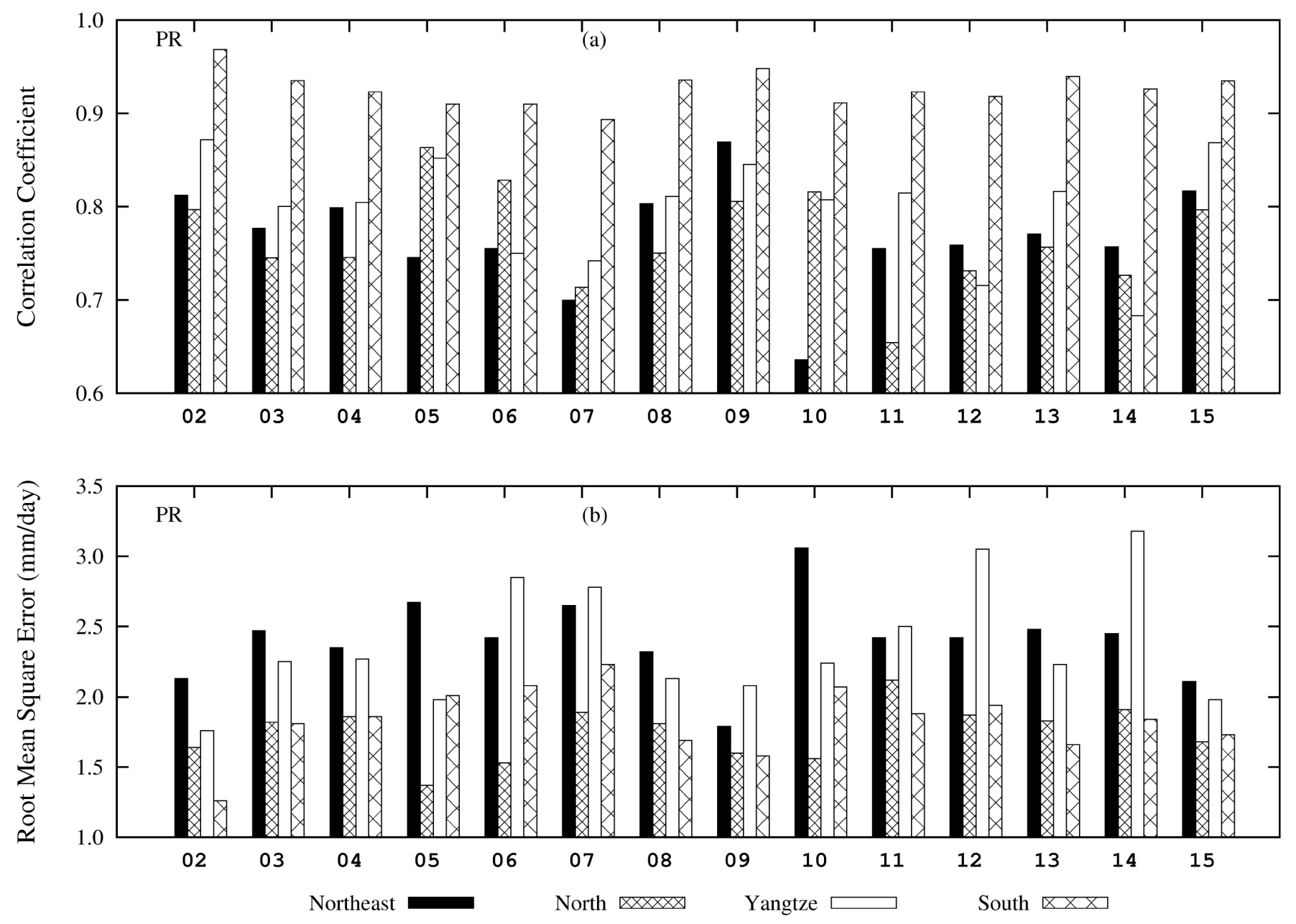

Fig. (2). The correlation coefficient (a) and root mean square error ( $\mathrm{mm} \mathrm{day}^{-1}$, b) daily mean precipitation variations between observation and each of the 15 cases during June, July and August averaged over the Northeast, North, Yangtze River Basin and South.

conditions can be used to determine the RCM skill dependence on ICs. To study the effect of LBC uncertainties, additional experiments were conducted using R-2, ERA, ERI and JRA, all starting on April 1 and ending on September 1, 1998. The temporal interval is 6 hour for all the four reanalyses. The spatial grid varies while all using equal longitude $\times$ latitude, $2.5^{\circ}$ for R-2 and ERA, $1.5^{\circ}$ for ERI, and $1.25^{\circ}$ for JRA. These simulations are compared to determine the RCM skill dependence on the uncertainties induced by LBCs. All the analyses are based on the RCM simulations of June, July and August.

\section{RCM SKILL DEPENDENCE ON ICS}

Precipitation and surface air temperature are the key variables generally used for RCM skill evaluation. The simulation started from April 1 is referred to as the control experiment (case 01), all other 14 realizations initialized from April 2 to 15 are compared with case 01 to depict the effect of ICs since they all are driven by identical LBCs. Fig. (2) illustrates the correlation coefficients (CC) and root mean square errors (RMS) for daily mean precipitation variations between case 01 and each of the 14 runs during June, July and August averaged over the Northeast, North, Yangtze River basin, and South (Fig. 1).
As compared with case 01, the South has the highest CC for all runs, between 0.89 (case 07) and 0.97 (case 02). In contrast, Northeast has the lowest CC, between 0.64 (case 10) and 0.87 (case 09), both of which are much lower than those for South. Consistently, South generally has the lowest RMS between 1.26 (case 02) - 2.23 (case 07) $\mathrm{mm} \mathrm{day}^{-1}$, while the Northeast has highest RMS between 1.79 (case 09) - 3.06 (case 10) $\mathrm{mm} \mathrm{day}^{-1}$. There exists no obvious relationship of either CC scores or RMS errors with starting dates for all the four regions.

The 1998 summer flood was induced by severe rainfall events which were mainly determined by convective processes in the South. On the other hand, precipitation in the Northeast is largely generated through synoptic weather processes, such as front passages and cyclone activities. As a result, the precipitation simulation in the South is less sensitive to ICs producing much higher $\mathrm{CC}$ than the Northeast.

Fig. (3) shows the same statistics for surface air temperature as that for precipitation. The Northeast has the highest CC for all 14 runs while the Yangtze River Basin has the lowest $\mathrm{CC}$ for most runs. The $\mathrm{CC}$ ranges among the 14 runs for the four regions, however, are generally very small, indicating that the sensitivity of surface air temperature simulation to ICs is weak. As for RMS, the South has the 

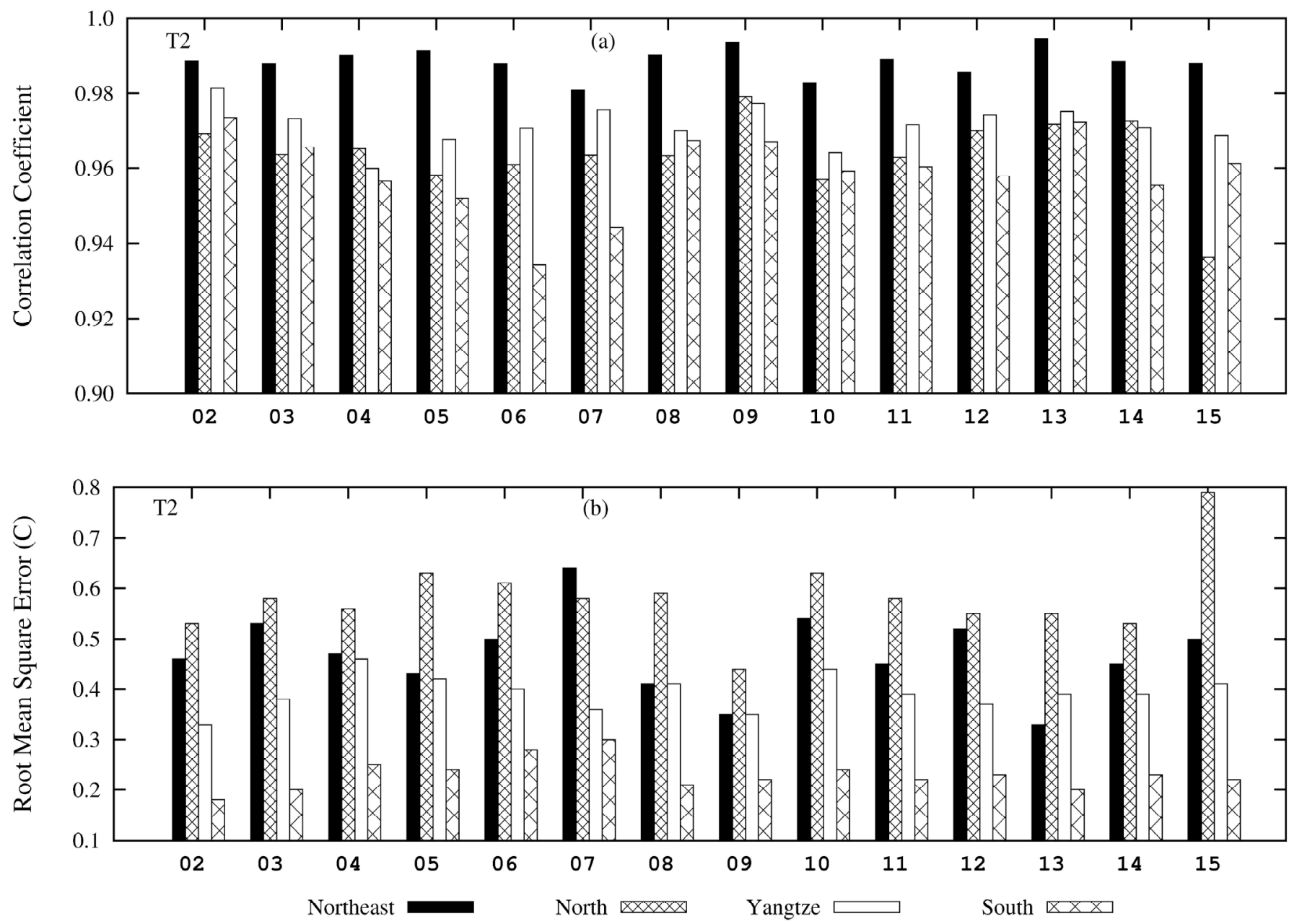

Fig. (3). The correlation coefficient (a) and root mean square error $\left({ }^{\circ} \mathrm{C}, \mathbf{b}\right)$ daily mean surface air temperature variations between observation and each of the 15 cases during June, July and August averaged over the Northeast, North, Yangtze River Basin and South.

smallest values for all 14 runs, while the North has the largest values for all the cases except 07 . The RMS ranges are also very small among the 14 runs for the four regions. The smaller CC and RMS ranges showed in Fig. (3) than those in Fig. (2) suggest that ICs have much less effect on surface air temperature than precipitation, which are consistent with previous studies (Giorgi and $\mathrm{Bi}$ [5]; Christensen et al. [26]).

A question is whether the ensemble mean of all runs with perturbed ICs improves the RCM performance over the individual realizations. Fig. (4) compares with observations the geographical distributions of 1998 summer (June, July and August) mean precipitation and surface air temperature for case 01 (R-2, hereafter), and the ensemble average (IC_ENS) of all 15 runs. The patterns for the R-2 and IC_ENS closely resemble each other for both precipitation and surface air temperature. Both fail to reproduce the southwest-northeast main rainbelt along the Yangtze River Basin, but successfully simulate the South and Northeast centers. Both can depict the general temperature pattern (e.g., the warm center over the Yangtze River Basin and North China, Sichun Basin), but produce systematic cold biases of $4^{\circ} \mathrm{C}$. A comparison of the spatial frequency distribution for summer mean biases in precipitation and surface air temperature over all grids east of $100^{\circ} \mathrm{E}$, where observations are abundant, shows no overall difference between IC_ENS and R-2 and all other IC runs. These results indicate that the ensemble mean has little improvement than individual realizations as far as the 1998 summer seasonal averages concerned.

Fig. (5) compares daily mean precipitation variations during June 1 - August 30 averaged over the four regions between the R-2 and IC_ENS with observations. Again, the R-2 and ENS closely resemble each other over all regions. The correlations with observations over the Northeast, North, Yangtze River Basin, South are 0.01, 0.34, 0.37, 0.39 for the R-2 and $0.02,0.37,0.45,0.39$ for the IC_ENS. Thus the IC effect is small even for daily precipitation evolution. This is more so for surface air temperature.

All of the above statistical measures demonstrate that the effect of perturbed ICs is trivial, and thus their ensemble mean shows little improvement in the RCM downscaling skill. This results from the dominant control by the driving LBCs throughout the entire integration period. The effect from IC perturbations quickly dissipates and plays minor role after the spin-up period, typically of $\sim 10$ days (Giorgi and Mearns [27]; Wu et al. [7]). 

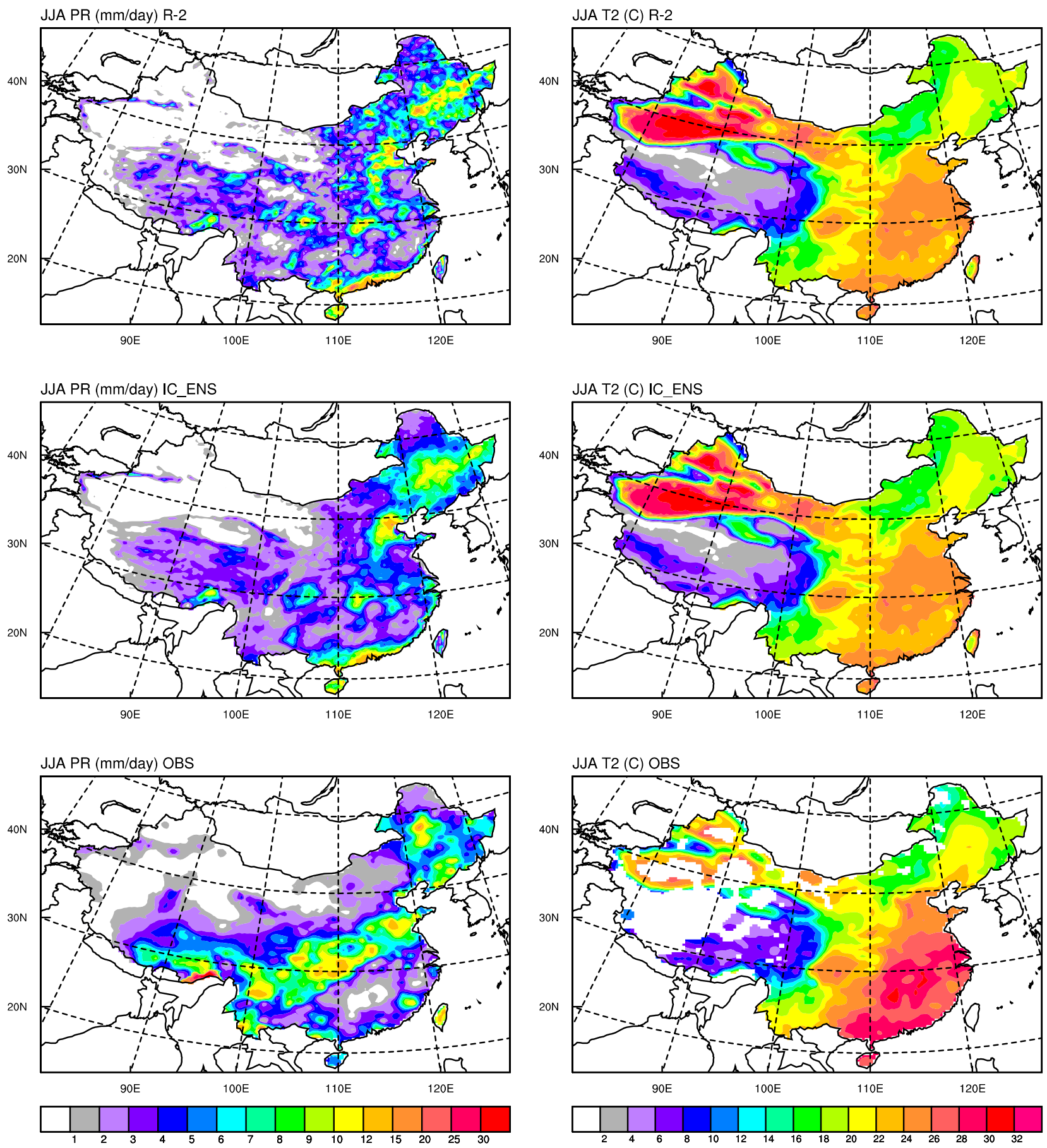

Fig. (4). Geographical distributions of summer mean precipitation $\left(\mathrm{mm}\right.$ day ${ }^{-1}$, left $)$ and surface air temperature $\left({ }^{\circ} \mathrm{C}\right.$, right $)$. Simulated in case 01 (R-2, top), as the ensemble mean of 15 runs (IC_ENS, middle) and observed (OBS, bottom).

\section{RCM SKILL DEPENDENCE ON LBCS}

The RCM downscaling results are constrained by the large-scale atmospheric circulation forcings through dynamic relaxation of the LBCs. The RCM domain has been objectively chosen to correctly represent the internal mesoscale physical processes while minimizing the impact of LBC errors such that the observed spatial distributions and temporal variations of near surface climate can be realistically simulated at regional-local scales (Liang et al. [4]; Liu et al. [14]). The LBC errors which are from largescale reanalyses uncertainties, however, can still be transferred into the RCM domain to affect the downscaling skill. Fig. (6) shows $925 \mathrm{hPa}$ relative humidity correlation coefficients between R-2 and ERA, ERI, JRA based on daily averages during June 1 - August 30, the values for 

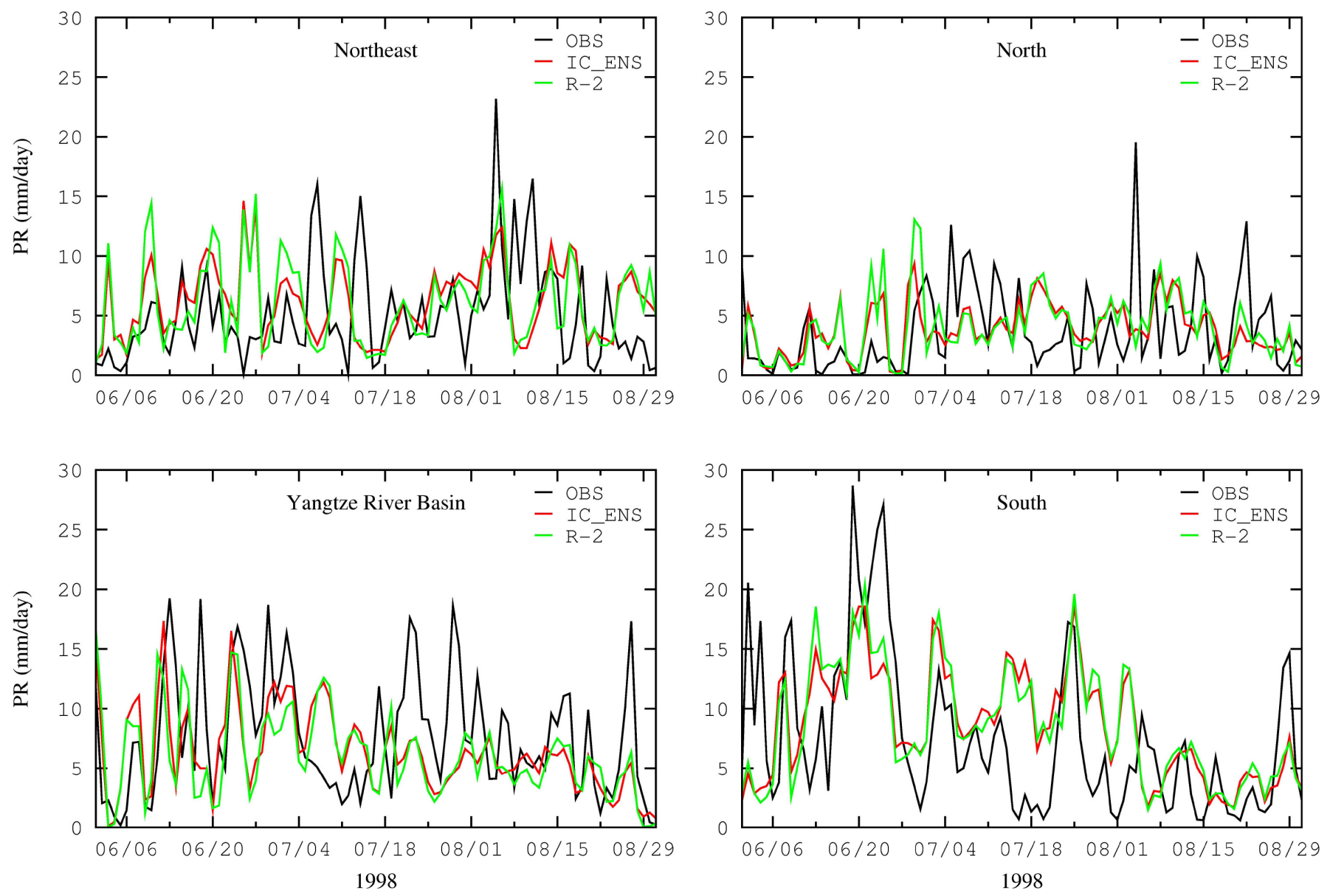

Fig. (5). Daily mean precipitation variations during June 1 to August 30 averaged over the four key regions for observations (OBS), ensemble mean (IC_ENS) and case 01 (R-2).

confidence level $95 \%$ and $99 \%$ by Student's one-sided t-test are 0.21 and 0.27 respectively. The three correlation coefficient fields showed similar geographical distribution patterns. Correlation coefficient that passed the $99 \%$ confidence level mainly occurred over land except Tibet Plateau. Most of the east China where observations are abundant has high values that are over 0.8 or even 0.9 . Very low even negative correlation coefficient values are occurred over tropical oceans and failed to pass the $95 \%$ confidence level. These substantial differences indicate inconsistency between the large-scale reanalyses, typically over the areas where observational data are lacking. LBCs constructed from these large-scale reanalyses within the problematic areas resulted in $\mathrm{LBC}$ errors which are integrated into the RCM domain and impact the RCM performance.

Fig. (7) compares daily mean precipitation variations during June 1 - August 30 averaged over the four regions as observed and downscaled by the RCM from the R-2, ERA, ERI, JRA as well as the ensemble averages (LBC_ENS) of the four runs. Over the Northeast, large discrepancies between the RCM simulations mainly occurred during the end of June and early July, where all runs and the ensemble average failed to reproduce the observation. On the other hand, over the North, the differences between individual runs and LBC_ENS are small in June and July, but larger in August. Over the Yangtze River Basin, the discrepancies between the runs are large in June, while relatively small in July and August. Over the South, large spreads between the runs occurred throughout the whole summer.

Table 1 lists the CC and RMS scores of the regional mean daily precipitation and surface air temperature downscaled by the RCM form 4 reanalyses as compared with observations. For precipitation, all runs has poor performance over the Northeast and North (failed to pass the Student's one-sided t-test $95 \%$ confidence level), while over the Yangtze River Basin and South, the simulation driven by the R-2 is the best (passed the 99\% confidence level). Especially over the South, the R-2 driven run has CC of 0.45 , much higher than other runs and the ensemble average. For surface air temperature, both the CC and RMS measures indicate substantially better skill scores (all passed 99\% confidence level) and smaller spreads among runs than precipitation. For both precipitation and temperature, the ensemble mean does not improve the RCM skill over the individual runs driven by R-2, ERA, ERI or JRA.

The effect of LBC uncertainties on precipitation is the largest over the Northeast and smallest over the South, which is similar to that of IC uncertainties. This regional contract occurs because precipitation is mainly produced by local convective processes in the South rather than by synoptic weather systems in the Northeast as controlled by large-scale circulations. 
(a) CC RH925 R-2 \& ERA

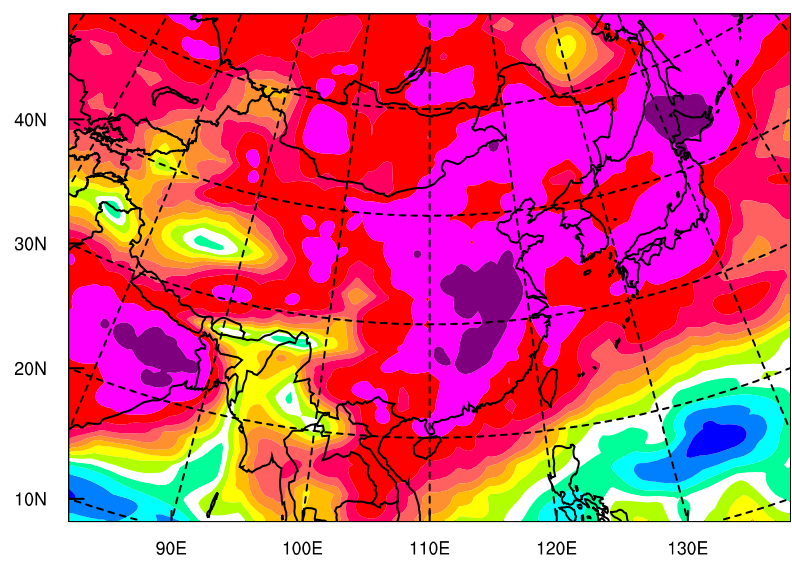

(b) CC RH925 R-2 \& ERI

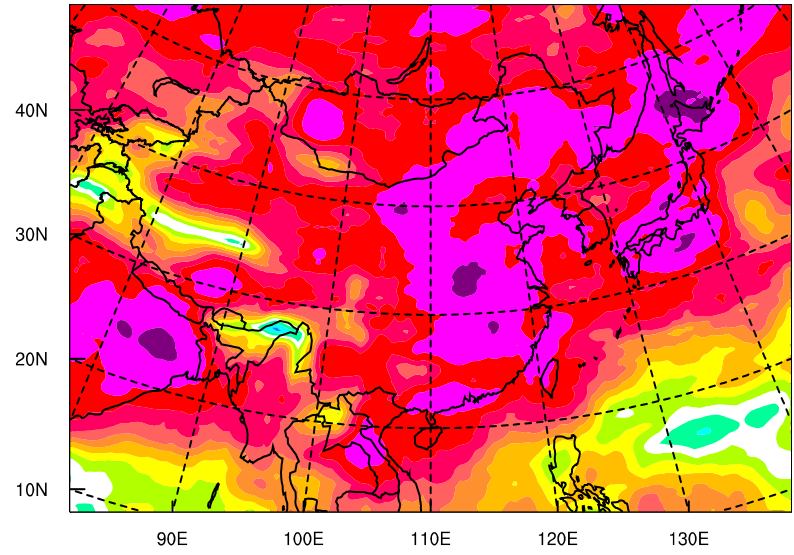

(c) CC RH925 R-2 \& JRA

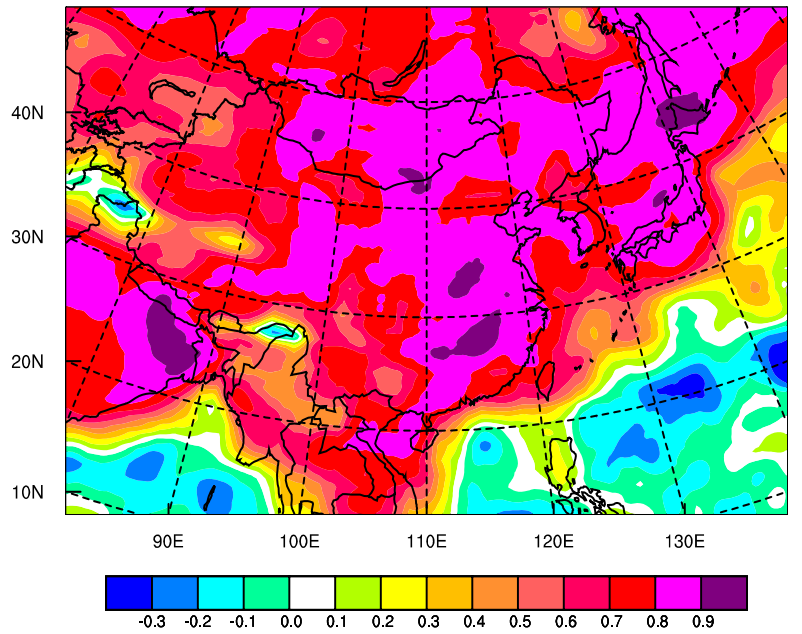

Fig. (6). Geographical distribution of correlation coefficient (CC) for relative humidity (RH) on $925 \mathrm{hPa}$ between R-2 and ERA (a), ERI (b) and JRA (c).

Fig. (8) shows the geographical distributions of summer mean precipitation downscaled by the RCM from ERA, ERI, JRA reanalyses and the ensemble average of the four RCM runs (LBC_ENS). They can be compared with the R-2 and observations in Fig. (4). In contrast to the IC perturbations that generate little sensitivity, the LBCs from the R-2, ERA,
ERI and JRA produce notable differences in precipitation geographic distributions. In particular, the R-2 run has less precipitation than all other runs over the Northeast, North and South. All runs driven and their ensemble average fail to reproduce the observed main rainbelt oriented from the southwest to northeast over the Yangtze River Basin. The R2 LBCs drive the RCM to result in more realistic downscaling over the South where the other three forcings (especially ERA) lead to excessive precipitation. Again, the ensemble average of the four runs does not improve the overall RCM downscaling performance.

\section{DISCUSSION AND CONCLUSION}

The RegCM3 downscaling skill dependence on initial conditions is examined by comparing summer simulations driven by R-2 starting from consecutive dates from April 1 15,1998 . The results showed that the IC perturbations have certain influences on daily variations of precipitation and surface air temperature, but little effect on seasonal mean geographical distributions. The ensemble mean of the 15 runs does not produce overall superior RCM skill to individual realizations. Simulation of precipitation is more sensitive to ICs than surface air temperature.

On the other hand, the RegCM3 exhibits stronger dependence on LBC forcings than IC perturbations. Four simulations driven by R-2, ERA, ERI and JRA, all starting on April 1, contain large discrepancies in both daily variations and summer mean geographical distributions of precipitation. The RegCM3 driven by the ERA generally produces more precipitation than that by the R-2, ERI and JRA over most of the domain. The ensemble mean of the four runs has little skill enhancement to the individuals.

The above conclusion has two important limitations. First, our results on both IC and LBC ensemble means were based on simple averaging (with an equal weight) of all realizations. They did not produce significant skill enhancement to individual realizations. On the other hand, the optimized physics ensemble is likely an effective approach to achieve significant skill improvement, especially for precipitation as demonstrated by Liang et al. [28] and Liu et al. [15]. Second, the RCM downscaling skill also strongly depends on model physics, especially the parameterizations of subgrid processes like cumulus convection (Liang et al. [28]). For short-range synoptic-scale precipitation forecasts, Clark et al. [29] found that model errors due to physics representations are greater than those from IC or LBC uncertainties. The sensitivity of RCM physics configuration and the optimization of ensemble weighting require further investigation. While improve RCM skill through initial and lateral boundary conditions and their ensemble are not recommended.

\section{ACKNOWLEDGEMENTS}

This research was supported in part by the USDA Cooperative State Research, Education, and Extension Service (CSREES) AG CSU G-1469-1 and the NOAA Education Partnership Program (EPP) COM Howard 631017. The views expressed are those of the authors and do not necessarily reflect those of the sponsoring agencies and the Earth System Science Interdisciplinary Center. 

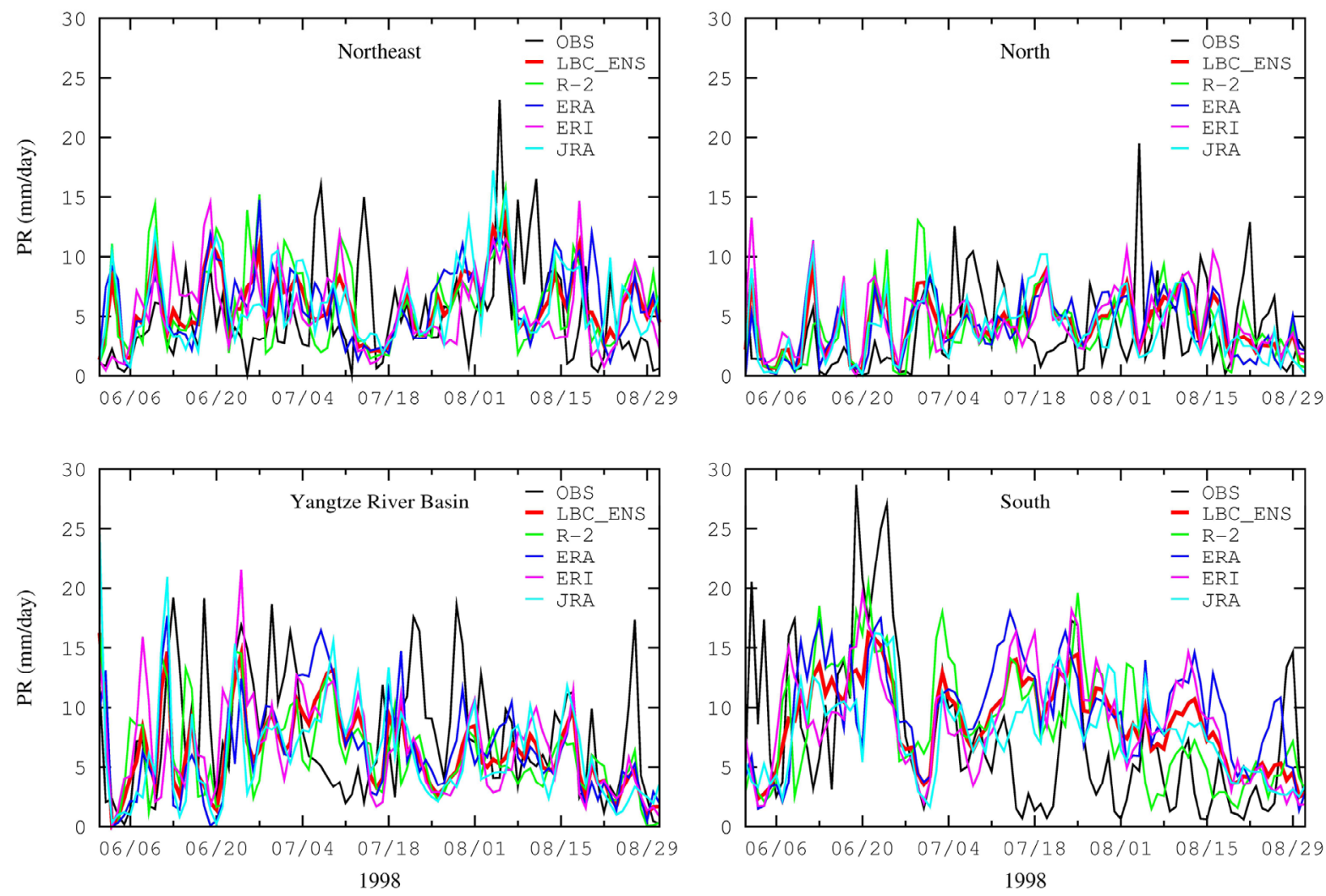

Fig. (7). Daily mean precipitation variations during June 1 to August 30 averaged over the four key regions for observations (OBS), RCM simulates driven by the R-2, ERA, ERI and JRA as well as their ensemble mean (LBC ENS).

Table 1. Statistics of Precipitation and Surface Air Temperature Downscaled by the RCM from the R-2, ERA, ERI and JRA as well as the Ensemble Mean of the Four Runs (LBC_ENS). Shown are Correlation Coefficients (CC) and Root Mean Square Error (RMS) of Simulated with Observed Daily Means Averaged Over the Four Key Regions

\begin{tabular}{|c|c|c|c|c|c|}
\hline & & \multicolumn{2}{|c|}{ Precipitation } & \multicolumn{2}{|c|}{ Surface Air Temperature } \\
\hline & & $\mathrm{CC}$ & $\operatorname{RMS}\left(\mathbf{m m}\right.$ day $\left.^{-1}\right)$ & $\mathrm{CC}$ & $\operatorname{RMS}\left({ }^{\circ} \mathbf{C}\right)$ \\
\hline \multirow{5}{*}{ Northeast } & $\mathrm{R}-2$ & $0.01^{*}$ & 5.56 & 0.80 & 2.62 \\
\hline & ERA & 0.15 & 4.90 & 0.82 & 2.53 \\
\hline & ERI & 0.15 & 4.87 & 0.84 & 2.16 \\
\hline & JRA & 0.14 & 4.98 & 0.82 & 2.30 \\
\hline & LBC_ENS & 0.13 & 4.68 & 0.83 & 2.37 \\
\hline \multirow{5}{*}{ North } & $\mathrm{R}-2$ & 0.12 & 4.19 & 0.70 & 2.21 \\
\hline & ERA & 0.09 & 4.18 & 0.71 & 2.21 \\
\hline & ERI & 0.03 & 4.44 & 0.72 & 2.30 \\
\hline & JRA & 0.13 & 4.14 & 0.68 & 2.17 \\
\hline & LBC_ENS & 0.11 & 3.98 & 0.73 & 2.14 \\
\hline \multirow{5}{*}{$\begin{array}{c}\text { Yangtze } \\
\text { River } \\
\text { Basin }\end{array}$} & $\mathrm{R}-2$ & 0.28 & 5.44 & 0.68 & 2.85 \\
\hline & ERA & 0.18 & 5.94 & 0.66 & 2.70 \\
\hline & ERI & $0.26^{* *}$ & 5.55 & 0.56 & 2.87 \\
\hline & JRA & 0.14 & 6.29 & 0.68 & 2.73 \\
\hline & LBC_ENS & 0.25 & 5.39 & 0.67 & 2.75 \\
\hline \multirow{5}{*}{ South } & $\mathrm{R}-2$ & 0.45 & 6.13 & 0.67 & 3.33 \\
\hline & ERA & 0.15 & 7.48 & 0.62 & 3.03 \\
\hline & ERI & 0.30 & 6.72 & 0.66 & 3.14 \\
\hline & JRA & 0.34 & 6.20 & 0.70 & 3.04 \\
\hline & LBC_ENS & 0.38 & 6.17 & 0.70 & 3.12 \\
\hline
\end{tabular}


(a) PR (mm/day) ERA

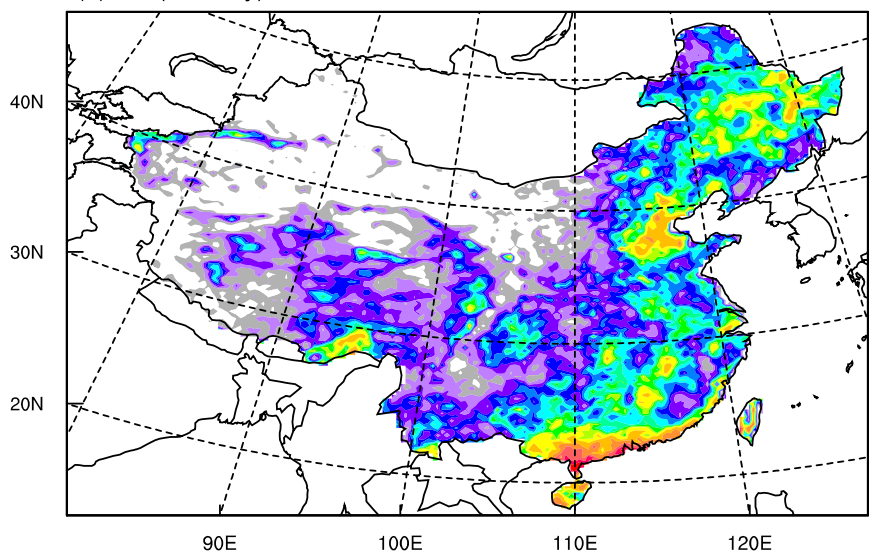

(c) JJA PR (mm/day) JRA

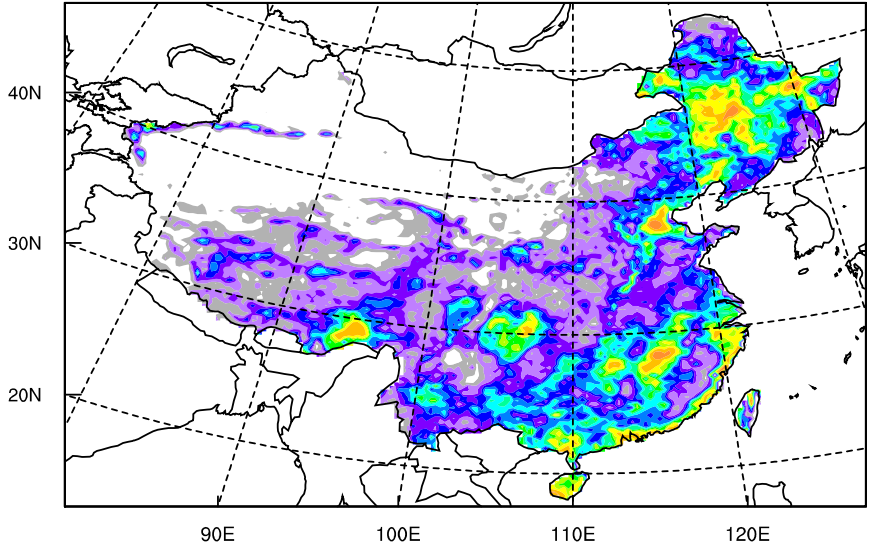

(b) JJA PR ( $\mathrm{mm} /$ day) ERI

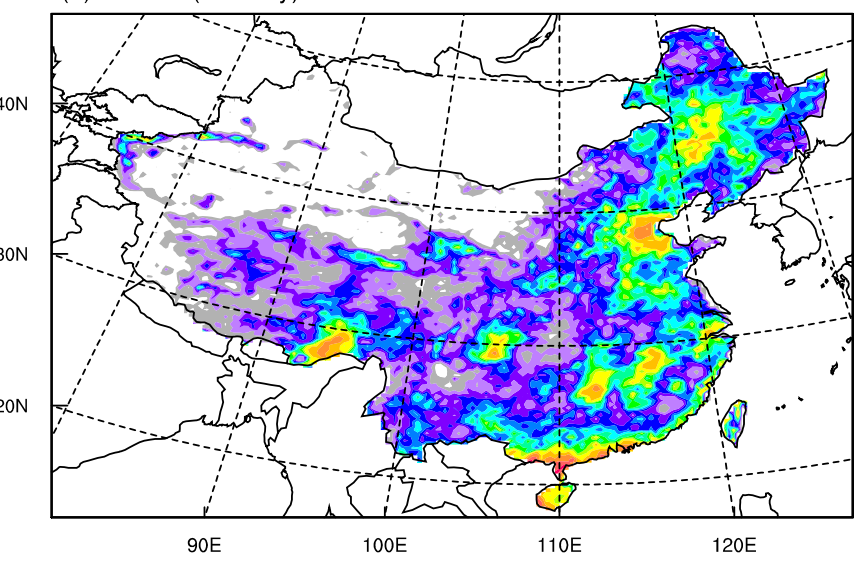

(d) JJA PR (mm/day) LBC_ENS

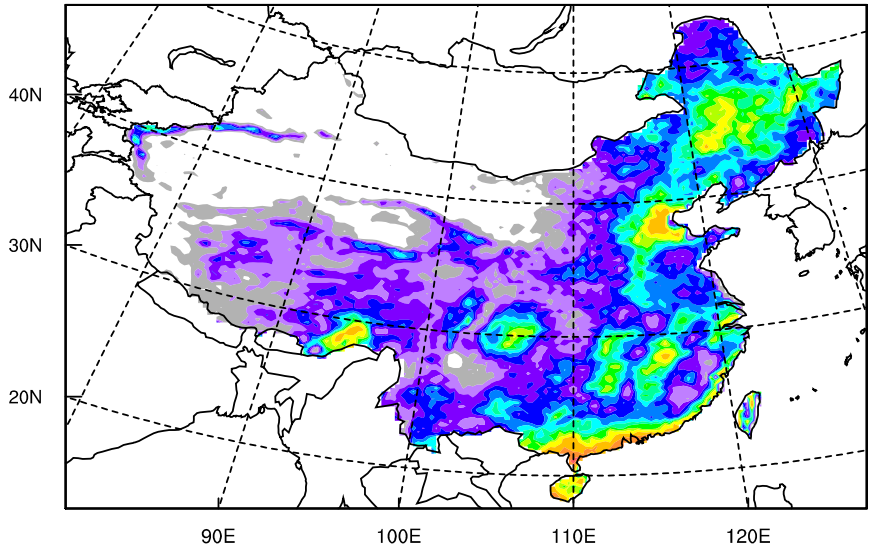

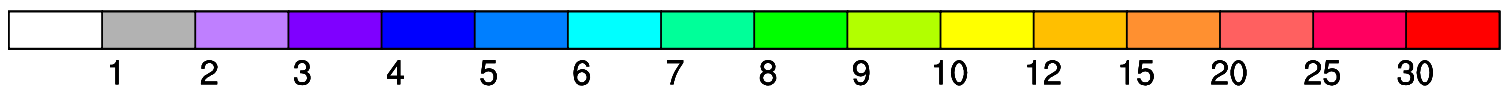

Fig. (8). Geographical distribution of summer mean precipitation ( $m m$ day $\left.^{-1}\right)$ simulated driven by ERA (a), ERI (b), JRA (c) and as the ensemble average (LBC_ENS, (d)) of the four runs driven by R-2, ERA, ERI and JRA.

\section{CONFLICT OF INTEREST}

None declare.

\section{REFERENCES}

[1] Lorenz EN. A study of the predictability of a 28-variable atmospheric model. Tellus 1965; 17: 321-33.

[2] Toth Z, Kalnay E. Ensemble forecasting at NMC: the generation of perturbations. Bull Am Meteorol Soc 1993; 74: 2317-30.

[3] Mullen SL, Du J, Sanders F. The dependence of ensemble dispersion on analysis forecast system implications to short-range ensemble forecasting of precipitation. Mon Weather Res 1999; 127: $1674-86$

[4] Liang X-Z, Kunkel KE, Samel AN. Development of a regional climate model for U.S. Midwest applications. Part I: sensitivity to buffer zone treatment. J Climate 2001; 14: 4363-78.

[5] Giorgi F, Bi X. A study of internal variability of a regional climate model. J Geophys Res 2000; 105: 29503-21.

[6] Warner TT, Peterson RA, Treadon RE. A tutorial on lateral boundary conditions as a basic and potentially serious limitation to regional numerical weather prediction. Bull Am Meteorol Soc 1997; 78: 2599-617.

[7] $\mathrm{Wu} \mathrm{W}$, Lynch AH, Rivers A. Estimating the uncertainty in a regional climate model related to initial and lateral boundary conditions. J Climate 2005; 18: 917-33.
[8] Gibson JK, Kållberg P, Uppala S, et al. ERA description. ECMWF Re-Analysis Project Report Series, No. 1, ECMWF, Reading, United Kingdom 1997

[9] Kanamitsu M, Ebisuzaki W, Woolen J, et al. The NCEP-DOE AMIP-II reanalysis (R-2). Bull Am Meteorol Soc 2002; 83: 163143.

[10] Dee DP, Uppala SM, Simmons AJ, et al. The ERA-Interim reanalysis: configuration and performance of the data assimilation system. Q J R Meteorol Soc 2011; 137: 553-97.

[11] Onogi K, Tsutsui J, Koide H, et al. The JRA-25 Reanalysis. J Meteorol Soc Japan 2007; 85: 369-432.

[12] Samel AN, Liang X-Z. Understanding relationships between the 1998 Yangtze River flood and northeast Eurasian blocking. Climate Res 2003; 23: 149-58.

[13] Wang YQ, Sen OL, Wang B. A highly resolved regional climate model (IPRC-RegCM) and its simulation of the 1998 severe precipitation event over China. Part I: Model description and verification of simulation. J Climate 2003; 16: 1721-38.

[14] Liu S, Liang X-Z, Gao W, Zhang H. Application of climateweather research and forecasting model (CWRF) in China: domain optimization. Chin Atmos Sci 2008; 32: 457-68.

[15] Liu S, Gao W, Xu M, Wang X, Liang X-Z. China summer precipitation simulations using an optimal ensemble of cumulus schemes. Front Earth Sci China 2009; 3: 248-57.

[16] Elguindi N, Bi X, Giorgi F, et al. RegCM Version 3.1 User's Guide, 2007. Available from: http://users.ictp.it/ pubregcm/Reg $\mathrm{CM} 3 /$ 
[17] Dudhia J, Gill D, Guo YR, Manning K, Wang W, Chriszar J. PSU/NCAR mesoscale modeling system tutorial class notes and user's guide: MM5 modeling system Version 3, 2000. Available from: http://www.mmm.ucar.edu/mm5/doc.html

[18] Grell G. Prognostic evaluation of assumptions used by cumulus parameterizations. Mon Weather Rev 1993; 121: 764-87.

[19] Pal JS, Small EE, Eltahir EAB. Simulation of regional-scale water and energy budgets: representation of subgrid cloud and precipitation processes with RegCM. J Geophys Res 2000; 105(D24): 29579-94.

[20] Kiehl JT, Hack JJ, Bonan GB, et al. Description of the NCAR community climate model (CCM3). NCAR Tech. Note NCAR/TN420+STR, National Center for Atmospheric Research, Boulder, Colorado, 1996; pp. 152.

[21] Holtslag AAM, Boville BA. Local versus nonlocal boundary-layer diffusion in a global climate model. J Climate 1993; 6: 1825-42.

[22] Dickinson RE, Henderson-Seller A, Kennedy PJ. BiosphereAtmosphere Transfer Scheme (BATS) version 1e as coupled to the NCAR community climate model. NCAR Tech Note NCAR/TN387+STR, National Center for Atmospheric Research, Boulder, $\mathrm{CO}, 1993 ; 72$.
[23] Giorgi F, Marinucci MR, Bates GT. Development of a second generation regional climate model (RegCM2) II: Convective processes and assimilation of lateral boundary conditions. Mon Weather Rev 1993; 121: 2814-32.

[24] Ding YH. Summer monsoon rainfall in China. J Meteorol Soc Jpn 1991; 70: 243-66.

[25] Samel AN, Wang WC, Liang X-Z. The monsoon rainband over China and relationship with the Eurasian circulation. J Climate 1999; $12: 115-31$.

[26] Christensen OB, Gaertner MA, Prego JA, Polcher J. Internal variability of a regional climate model. Clim Dyn 2001; 17: 87587.

[27] Giorgi F, Mearns LO. Introduction to special section: regional climate modeling revisited. J Geophys Res 1999; 104: 6335-52.

[28] Liang X-Z, Xu M, Kunkel K-E. Regional climate model simulation of U.S.-Mexico summer precipitation using the optimal ensemble of two cumulus parameterizations. J Climate 2007; 20: 5201-7.

[29] Clark AJ, Gallus WA Jr, Chen T-C. Contributions of mixed physics versus perturbed initial/lateral boundary conditions to ensemblebased precipitation forecast skill. Mon Weather Rev 2008; 136: 2140-56.

(C) Liu et al.; Licensee Bentham Open.

This is an open access article licensed under the terms of the Creative Commons Attribution Non-Commercial License (http: //creativecommons.org/licenses/by$\mathrm{nc} / 3.0 /$ ) which permits unrestricted, non-commercial use, distribution and reproduction in any medium, provided the work is properly cited. 